formability in sheet metal. The research center test outcomes have exhibited that the FLCs are influenced by a few variables containing strain rate $[7,8]$, strain hardening exponent and anisotropy coefficients $[9,10]$, grain size and microstructure [11] which are mostly influenced by heat treatment $[12,13]$, change in strain paths [14-16] and thickness $[17,18]$. After the introduction of the FLC idea by Keeler [19], many researchers have investigated on the sheet metal formability both by numerical and experimental methods [20-22].

Then again, the estimation of FLCs in THF is still an advancing field in view of the complications associated with the procedure. The significant methods of failures in this activity are expected to bursting and wrinkling. Bursting takes place because of expanded ductile deformation along its circumferential way. This prompts the arrangement of restricted necks which are commonly adjusted with the tube axis. The last failure occurs by parting or cracks within the neck. Then again, wrinkling happens if the cylinder is exposed to extreme axial feeds and may prompt hopeless folds in the final segment.

It is obvious from the arguments that few problems relating to THF should be watchfully explored. To begin with, most investigations expect comparative strain records which aren't sustained by the restricted experimental facts displayed by Asnafi and Skogsgardh [23]. This problem should be explained by constantly recording the strains in THF and furthermore by processing with numerical simulations. Aue-U-Lan et al. [24] investigated on the finite element simulations of THF for process optimization. From the work, it was concluded that the accurate prediction and reliability of the THF process is highly dependent on input material data. Jin et al. [25] investigated on the THF process using FE modeling for producing hollow crank shafts. Process parameters were optimized by considering kinematic hardening law. Internal pressure, feed rate and friction were considered to attain uniform thickness distribution over hollow crank tube. Numerical results were well in connection with the experimental results. Zhang et al. [26] explored different necking criterias in the sheet forming and Al 5086 sheet formability were studied based on the explored criterias implementing in the FE simulation. Both the experimental and numerical failures were well in connection with each other based on the explored necking criterias. Hashemi et al. [27] worked on the metal bellow forming process to predict the necking in the bellows by utilizing both stress and strain based forming limits. Both the forming limits were compared which were constructed by using experimental and theoretical methods. Gang et al. [28] developed a warm hydroforming die to impart non-uniform temperature gradient along the tube axis and from the designed die, the thickness distribution of the hydroformed tube were investigated. From the work, it was concluded that the imposing the suitable temperature gradient attained the uniform thickness distribution and also reduced the thickening of the tube at the end feeding sections.

Thanakijkasem et al. [29] investigated on the annealing consequence on the formability of the SS 304 tubes during THF process. Both experimental and numerical simulations were carried out to compare the results of fracture in tubes during hydroforming process. The work concluded that the annealing improved the tube deformation significantly with suitable tube expansion. Thanakijkasem et al. [30] compared three different FE models of THF with the experimental results of SS 304 tube hydroforming. Formability of the SS 304 tubes was investigated by the FLD of the formed tubes. The merits and demerits of the three models were explained and the accuracy with the experimental results was explained in their study. Naghibi et al. [31] presented a novel approach to predict the FLD of the SS 304 tubes during hydroforming process. The work explored the parametric effects on the strain path and concluded that the proposed method has a considerable role in predicting the formability during THF process.

As per the above literature survey, it is understood that numerous efforts were tried to establish the forming limit diagram (FLD) of as received material and few researchers have compared the as received with the heat treated FLD of tube forming. Based on the identified lacuna from the survey, the present study deals with the hydro-bulging of SS 304 with various bulge widths ( $L / D=1,1.25$ and 1.5). Three different boundary conditions were utilized to acquire the necking strains for a choice of strain paths to establish the FLD. Tensile tests were performed on the SS 304 specimens at three different heat treated conditions. The obtained tensile test data of the four specimens were utilized to conduct FE simulations. The simulations were performed for unusual strain paths up to bursting of the tubes. Three unusual L/D ratios and boundary situations were resulted in obtaining FLD points. The obtained FLD is compared with two different models in order to predict the accuracy of the FLD models. The main novelty of the current work is to compare the numerical solution in terms of internal pressure and FLD to the existed analytical models. The consequence of the heat treatment temperatures on the formability of SS 304 tubes during tube forming were also investigated in the present study. 


\section{Mathematical models}

\subsection{Modelling for internal pressure in tube hydroforming}

The theoretical model for the pressure necessary to form the tube in open tube bulge test is developed by Koc and Altan [32]. The theory for the pressure essential to bulge/form the tube has been derived analytically with similar assumption like membrane theory. The nomenclature of the tube dimensions is shown in Fig. 1a and hoop and longitudinal strains during the bulging of the thin walled tubular component

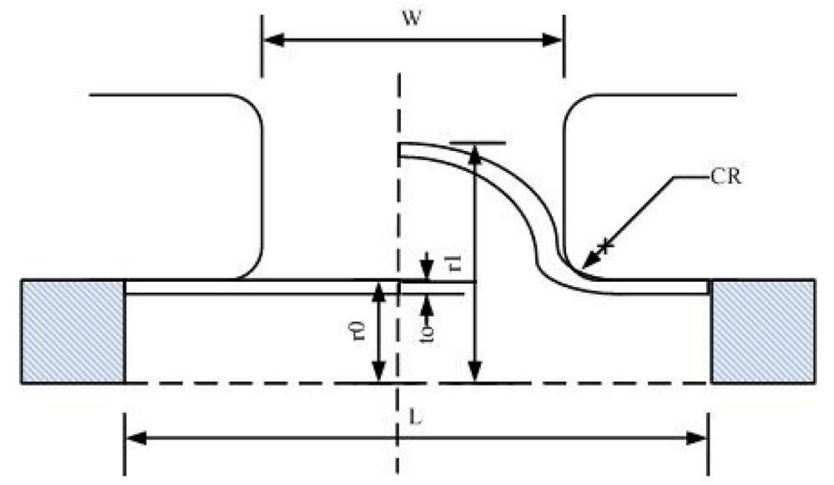

$\mathbf{a}$

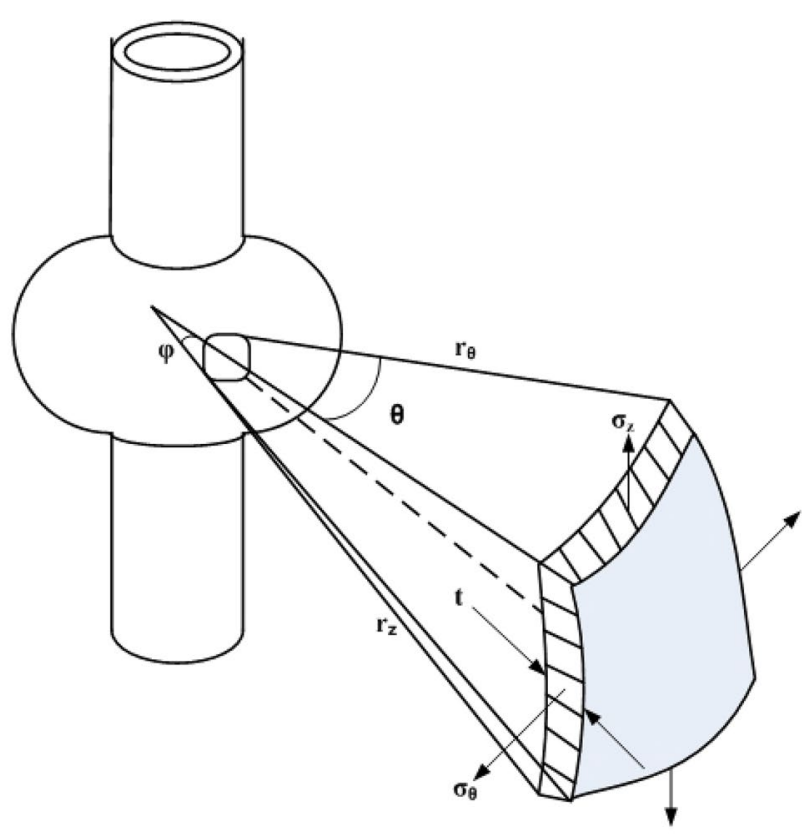

b

Fig. 1 Nomenclature of the $\mathbf{a}$ tube dimensions and $\mathbf{b}$ hoop and longitudinal strains during bulging of the tube [32] is redrawn from Koc and Altan [32] and is shown in Fig. 1b using membrane assumptions as given in Eq. 1 .

$\frac{P_{i}}{t}=\left\lfloor\frac{\sigma_{\theta}}{\rho_{1}}+\frac{\sigma_{z}}{\rho_{2}}\right\rfloor$

whereas $\mathrm{t}=$ wall thickness; $\mathrm{P}_{\mathrm{i}}=$ internal pressure; $\sigma_{\theta}=$ hoop stress; $\sigma_{\theta}=$ longitudinal stress

Curvatures radius in the direction of tangential and longitudinal for a cylindrical tube case will be

$\rho_{1}=r \rho_{2}=\infty$

Equation 1 can be rewritten by using Eq. 2 as

$\mathrm{P}_{\mathrm{i}}=\sigma_{\theta}\left(\frac{t_{1}}{r_{1}}\right)$

Tangential (hoop), Longitudinal and Radial directions strains of a tubular component be as follows:

$\varepsilon_{\theta}=\ln \left(\frac{d_{1}}{d_{0}}\right) \quad \varepsilon_{z}=\ln \left(\frac{l_{1}}{I_{0}}\right) \quad \varepsilon_{r} \ln \left(\frac{t_{1}}{t_{0}}\right)=\varepsilon_{t}$

whereas $d_{1}, l_{1}$ and $t_{1}$ are final diameter, final length, final thickness

Finally the radius and thickness is described as follows:

$r_{1}=r_{0} e^{\varepsilon_{0}} t_{1}=t_{0} e_{r}^{\varepsilon}=t_{0}\left(\frac{r_{1}}{r_{0}}\right)^{\frac{1+\alpha}{\alpha-2}}$

where a (stress ratio) $=\frac{\sigma_{z}}{\sigma_{\theta}}$

$\mathrm{P}_{\mathrm{i}}=\frac{\sigma_{f}}{\sqrt{i-\alpha+\alpha^{2}}} \frac{t_{0}}{r_{0}} e_{r}^{\varepsilon-\varepsilon_{\theta}}$

The flow stress of the material $\left(\sigma_{f}\right)$ is expressed as shown in Eq. 7:

$\sigma_{f}=K\left(\varepsilon_{0}+\bar{\varepsilon}\right)^{n}$

Substituting Eqs. 7 in 6, we obtain:

$\mathrm{P}_{\mathrm{i}}=\mathrm{K} \frac{\left(\varepsilon_{0}+\bar{\varepsilon}\right)^{n}}{\sqrt{1-\alpha+\alpha^{2}}} \frac{t_{0}}{r_{0}} e^{-\varepsilon_{\theta}(2+\alpha)}$

$\left(P_{i}\right)_{y p}=\frac{\sigma_{y p}}{\sqrt{1-\alpha+\alpha^{2}}} \frac{t_{0}}{r_{0}} e^{-\varepsilon_{\theta}(2+\alpha)}$

whereas $\varepsilon_{\theta}=$ degree of expansion

From Eq. 9 bulging and bursting pressure inside the tube is simplified as follows:

$\left(P_{i}\right)_{y p}=\sigma_{y p} \frac{2 t_{0}}{\left(2 R_{0}-t_{0}\right)}=\sigma_{u t s} \frac{2 t_{0}}{\left(D_{0}-t_{0}\right)}$ 


\subsection{NADDRG model}

For shortening the theoretical and experimental calculation of FLD and also for employing the FLD more simply in industries, the 'North American Deep Drawing Research Group' (NADDRG) commenced a practical equation for calculating the FLD in real time scenarios [33]. As per this model, the FLD is a combination of two lines passing by a point (f10) in the plane-strain state. The lines are drawn at left and right side of FLD with slopes of about $45^{\circ}$ and $20^{\circ}$ respectively. The equation in requisites of engineering strain for estimating the forming limit strain $\mathrm{f} 10$ can be expressed as:

$\varepsilon_{10}=\frac{\left(23.3+14.13 t_{o}\right) n}{0.21}$

whereas ' $t_{0}$ ' is blank thickness $(\mathrm{mm})$ and ' $n$ ' is strain hardening exponent.

\subsection{SING and RAO model}

Based on original Sing-Rao scheme, the forming limit stress curve (FLSC) can be acquired using the linear regression technique. This scheme takes mean plastic anisotropy ratio into account for calculation using below mentioned equation $[34,35]$.

Based on flow rule the surface limit strains (Eqs. 12 and 13) for diverse stress (or strain) ratio (Eq. 14) can be calculated as:

$\varepsilon_{1}=\left[\left(1+2 r_{m}\right)\left(\sigma_{1}-\sigma_{2}\right)+\left(\sigma_{1}+\sigma_{2}\right)\right] \lambda$

$\varepsilon_{2}=\left[-\left(1+2 r_{m}\right)\left(\sigma_{1}-\sigma_{2}\right)+\left(\sigma_{1}+\sigma_{2}\right)\right] \lambda$

where

$\lambda=\frac{\varepsilon_{e}}{2\left(1+r_{m}\right) \sigma_{e}}$

where $\sigma_{1}$ and $\sigma_{2}$ are major and minor true stresses respectively; $\varepsilon_{1}$ and $\varepsilon_{2}$ major and minor true strains respectively; $\varepsilon_{e}$ is the equivalent plastic strain and $r_{m}$ is the Normal anisotropic value

\subsection{Thickness gradient necking criterion (TGNC)}

To anticipate the forming limit strains originating from the simulations, the present work pursue the thickness gradient condition. During the THF process, a restricted neck is seen by the nearness of a basic neighborhood thickness gradient in the tube. Such an impression of the neck is autonomous of the strain path, forming rate and the tube metal (material properties). The critical neighborhood thickness gradient $\mathrm{R}_{\text {cri, }}$ exists at the on-set of an obvious nearby neck. After beginning of deformation of the tube, a thickness gradient, " $R_{\text {thickness gradient }}$ " creates in the deformation tube which is shown in Eq. 15.

$R_{\text {thickness gradient }}=\frac{\text { present thickness of necking element }}{\text { present thickness of neighbouring element }}$

As the tube starts bulging (forming), the thickness gradient continues to reduce from original value of 1.0. The thickness gradient goes on decrease at the on-set of localized necking and at a certain stage called diffused necking, it reaches a critical value.

$R_{c r i}=\frac{\text { present thickness of necking element }}{\text { present thickness of neighbouring element }} \leq 0.92$

From the work of Kumar et al. [36] and Nandedkar [37], the $R_{c r i}$ is experimentally estimated as 0.92 . If $R_{c r i}$ is less than or equal to 0.92 , the tube specimen is considered as necked.

\section{Materials and method}

This section presents the details of the materials and methods used to investigate the formability of tube during hydroforming process.

\subsection{Tube material}

The tube material used in the present study was SS 304 and the chemical composition of the SS 304 is shown in Table 1. The tensile test samples were cut according to ASTM E8 standard dimensions from the SS 304 tubes of $1 \mathrm{~mm}$ thickness using gas cutting machine. The dimensions of the tensile test specimens are shown in Fig. 2. A total of four samples were cut from four tubes at same rolling direction. Out of four samples, three samples were heat treated in an electrical furnace. The samples were heated at $150^{\circ} \mathrm{C}, 200^{\circ} \mathrm{C}$ and $250^{\circ} \mathrm{C}$ in the furnace and the samples of respective temperature were kept constant for $30 \mathrm{~min}$ inside the furnace. Later, the samples were cooled at room temperature.
Table 1 Chemical composition of SS 304 material

\begin{tabular}{llllllllll}
\hline Elements & $\mathrm{Cr}$ & $\mathrm{Ni}$ & $\mathrm{Mn}$ & $\mathrm{C}$ & $\mathrm{Si}$ & $\mathrm{S}$ & $\mathrm{Al}$ & $\mathrm{Cu}$ & $\mathrm{Fe}$ \\
\hline SS 304 (wt\%) & 17.91 & 8.94 & 1.78 & 0.016 & 0.492 & 0.031 & - & 0.041 & Balanced \\
\hline
\end{tabular}


Fig. 2 Dimensions of the tensile test specimen

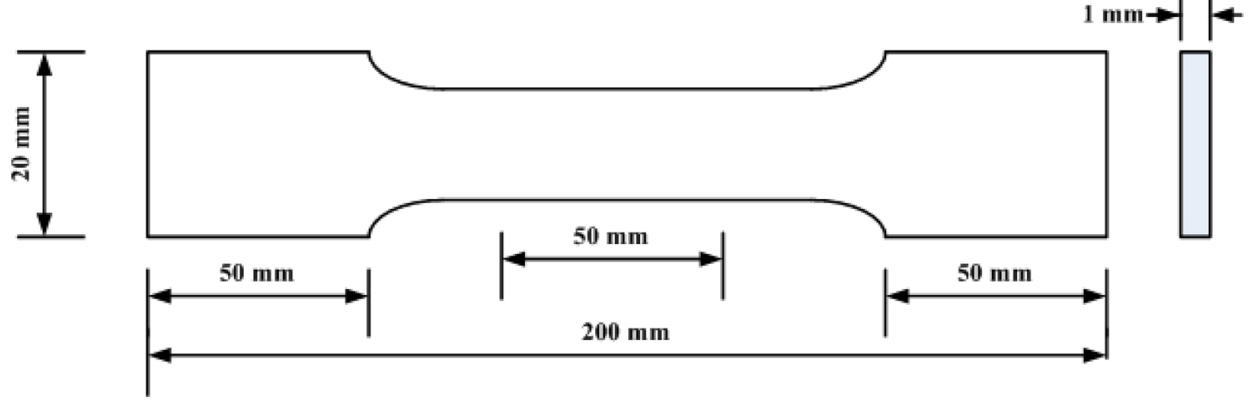

\subsection{Tensile testing}

All the Heat-treated samples with $50 \mathrm{~mm}$ gauge length, oriented at 0 degrees were tested in an INSTRON 3369; a computer controlled Universal Testing Machine (UTM) with a strain rate of $0.01 \mathrm{~mm} / \mathrm{s}$ at room temperature. Three samples were tested each of different heat treatment temperatures. The tensile test curves of all the four samples are plotted in Fig. 3. From the Fig. 3, it is observed that there is a decrease in yield strength and ultimate tensile strength of the heat treated samples. Increase in elongation was observed for $150^{\circ} \mathrm{C}$, further increase in temperature decreased the elongation. Increase in elongation leads to increase in strain hardening exponent for a temperature of $150^{\circ} \mathrm{C}$. Moreover, increase in annealing temperature reduced the strength coefficient when compared to as received condition. The study proved that the annealing of the test specimens reduced the yield strength and ultimate tensile strength of the specimens for all temperatures. This is because once the yield strength of the test specimen is reached; load increases drastically by attaining a plastic hardening and holds the constant value over a large elongation interval (16-45\%). This is well known that load decreases for larger deformation levels because of the reduction in transversal area at the necking zone. The load vs displacement data obtained from UTM is converted into true stress-strain curve and this true stress-true strain curves were fitted by the Hollomon power law to get the required mechanical properties for carrying out numerical simulations. The Hollomon law is defined in Eq. 17.

$\sigma=K \varepsilon^{n}$

whereas ' $K$ ' is the 'strength coefficient' and ' $n$ ' is 'strain-hardening (or work-hardening) exponent'. To be frank, strain is non-uniform in the gage length area and computing this true stress-strain curve is not meaningful for SS 304 sheets as it possesses higher engineering strains. As SS 304 is a ductile material it often have a true stress-strain relations which is further developed by Eq. 17 and is shown

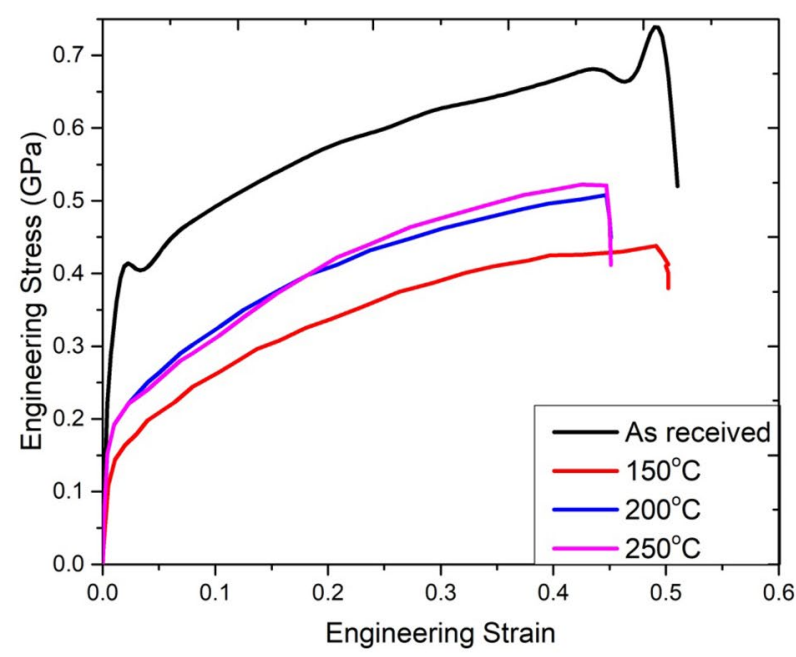

a

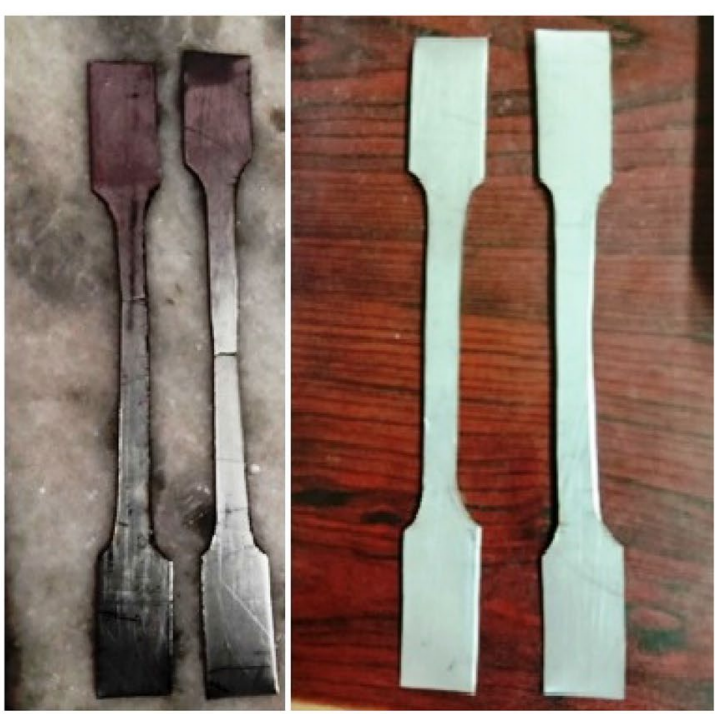

b

Fig. 3 a Tensile stress-strain curves at different heat treatment temperatures. $\mathbf{b}$ Prepared and fractured tensile test specimen 
in Eq. 18. From the Eq. 18, log-log curve for the true stress-strain curve is plotted for SS 304 sheet metal for various heat treated samples. From the curve, strain hardening exponent $(n)$ is calculated and which is a measure of resistance to necking. All the corresponding computed parameters are presented in Table 2.

$\log \sigma=\log K+n \log \varepsilon$

For attaining higher formability and defect free products, the material should have high yield strength to ultimate tensile strength ratio and also should have high elongation which was reported by Kalpakjian and Rajgopal [38]. Keeping this in view, investigations were carried out on heat treatment of SS 304 specimens to improve the formability by achieving the required mechanical properties.

\subsection{Numerical simulations for tube bulge test}

FE simulations are used in the metal forming area in order to optimize the process variables. Basically there are many process variables in any of the metal forming area, so optimization of these process variables are necessary to obtain defect free product by minimizing cost and time. Metal forming area consumes lot of time for performing trial and error tests to attain sound product, such that most of the material, time and cost is wasted. To overcome this problem, implementation of FEM simulations in this area is mandatory such that the design of tools and process variables can be altered based on the obtained results from simulations. There are many commercially available codes for carrying out the metal forming simulations. The FEM software used in the present study is PAM-STAMP $2 \mathrm{G}$. The tools essential for carrying out the THF simulations were modeled in CATIA V5R21. The modeled tools were imported into the analysis software PAM-STAMP $2 \mathrm{G}$ and surface mesh was generated over the tools. Tube was meshed with elastic-plastic quadrilateral shell elements of Belytschko-Tsay with a mesh size of 2 in order to attain accurate results [39]. Die and axial plungers were considered as rigid bodies, whereas tube was considered as deformable body. The input material properties for the tube material (SS 304) were found by the tensile tests using UTM as explained in Sect. 3.2. The material properties used for carrying out the simulations for different heat treatment temperatures are shown in Table 2. Three different boundary conditions were used to attain diverse strain paths: (1) fixed expansion (2) free expansion and (3) axial feed expansion of tubes with different L/D ratios. Detailed explanation of the boundary conditions were explained elsewhere [40]. The pressure feed curve used to simulate the THF process of the present work was considered based on the literature studies [40] and is shown in Fig. 4. The TGNC based criterion was employed for establishing the limit strains in the simulations. All the simulations were carried out by applying Hills 1948 yield theory with Hollomans flow stress characteristic as explained in the previous work of the author [41, 42].

\subsection{Forming limit diagram (FLD)}

FLD is very significant tool for the categorization of strain up to which the tube can deformed without failures (necking, bursting and wrinkling) as explained in the literature [4]. Different strain states were possible with variations in the boundary conditions and strain paths by various loading conditions as explained in the literature [43,44].

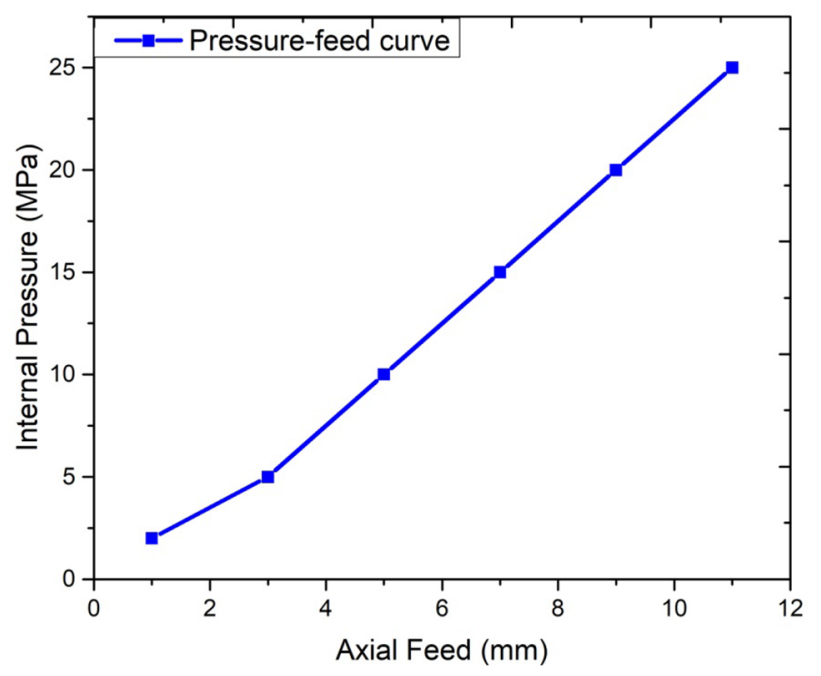

Fig. 4 Pressure-feed curve used for performing simulations
Table 2 Mechanical Properties of SS 304 sheets

\begin{tabular}{llllllll}
\hline $\begin{array}{l}\text { Heat treatment } \\
\text { temperature }\end{array}$ & $\mathrm{R}_{0}$ & $\mathrm{R}_{45}$ & $\mathrm{R}_{90}$ & $\sigma_{\mathrm{y}}(\mathrm{MPa})$ & $\mathrm{E}(\mathrm{GPa})$ & $\mathrm{K}(\mathrm{MPa})$ & $\mathrm{n}$ \\
\hline As received & 1.08 & 0.96 & 1.05 & 360 & 210 & 1417 & 0.403 \\
$150^{\circ} \mathrm{C}$ & & & & 325 & & 1041 & 0.376 \\
$200^{\circ} \mathrm{C}$ & & & & 351 & & 1285 & 0.395 \\
$250^{\circ} \mathrm{C}$ & & & & 349 & & 1199 & 0.385 \\
\hline
\end{tabular}


Construction of forming limit diagram is made possible by joining through necked region called forming limit curve. Forming limit strains were evaluated during THF process in the present study using numerical simulations for tube bulge test. Internal hydraulic pressure was used to bulge the tubes with different boundary conditions (axial plungers for feeding the tube) and aspect (L/D) ratios. All the tests with various boundary conditions were simulated using FE based code. A novel TGNC as enlightened in Sect. 2.4 were utilized for the prediction of the limit strains in the simulations.

\section{Results and discussion}

\subsection{Influence of heat treatment temperatures on internal pressure}

Figure 5 shows the heat treatment temperatures effect on the forming pressure required during tube bulge test. From the Fig. 5, it is observed that the forming pressure required to bulge the tube is reduced drastically when compared to as received condition, similar results were observed in the literature as well [45]. The pressure required to bulge or burst the tube depends mainly on the strength of the tube; which was altered by the heat treatment temperatures. The bursting pressure increased over $200^{\circ} \mathrm{C}$, whereas the bulging pressure is almost equal for both 200 and $250^{\circ} \mathrm{C}$ heat treatment temperatures. Figure 6 illustrates the comparison of maximum internal pressure required to bulge the tube before fracture for both numerical and analytical solution. The decrease in internal

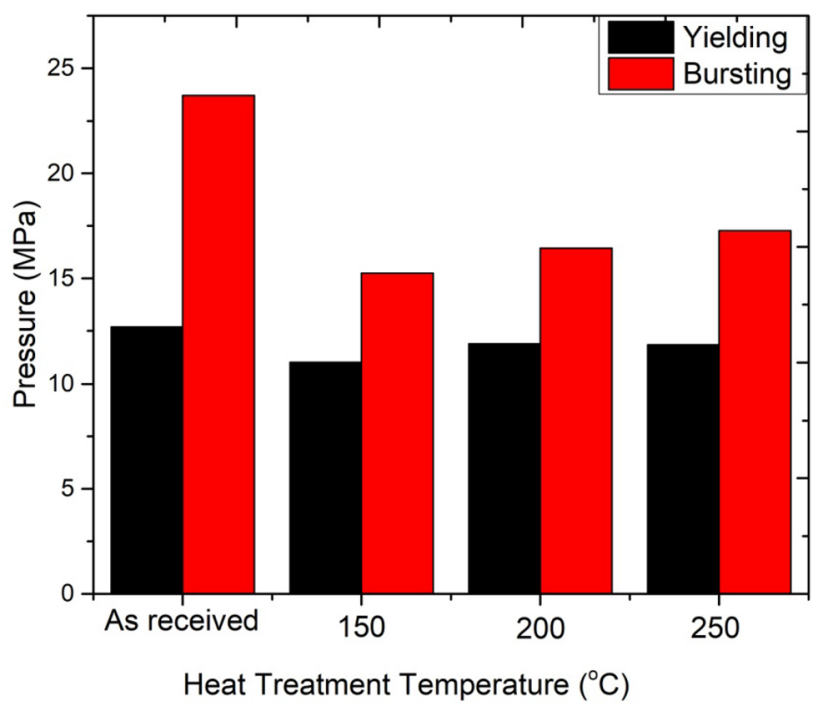

Fig. 5 Heat treatment temperatures effect on internal pressure of THF

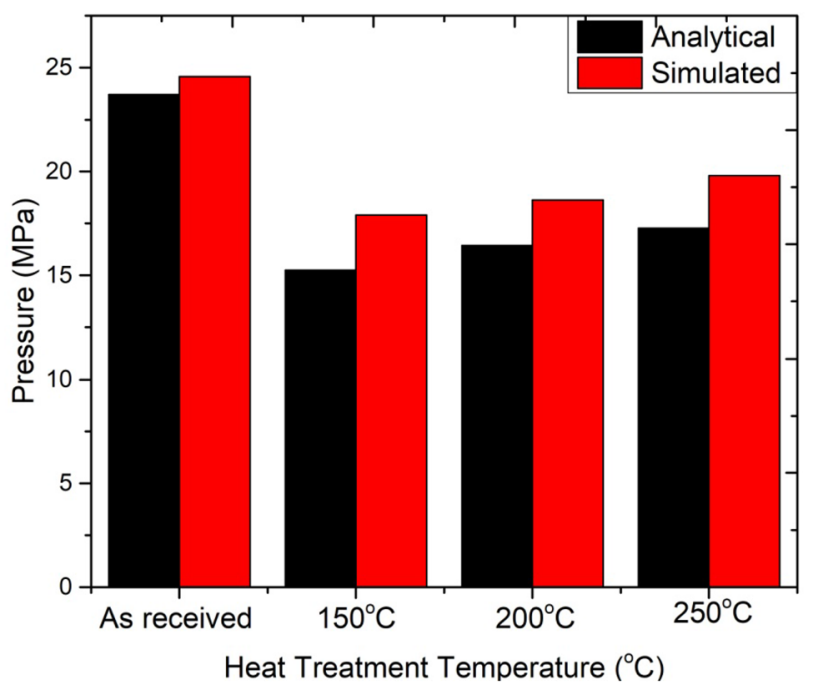

Fig. 6 Comparison of heat treatment temperatures effect on internal pressure for analytical and numerical simulation

pressure with heat treatment temperature is due to material softness with heat treatment.

The difference between analytical and numerical solution is less, which is around $5-10 \%$ for all the heat treatment temperatures. The decrease in internal pressure with heat treatment temperature of $150^{\circ} \mathrm{C}, 200^{\circ} \mathrm{C}$ and $250^{\circ} \mathrm{C}$ are $35.6 \%, 30.6 \%, 27 \%$ respectively when compared to as received condition. Slight increase in internal pressure is observed for temperatures of $200{ }^{\circ} \mathrm{C}$ and $250^{\circ} \mathrm{C}$, which owes to enhance in strength of material due to the heat treatment temperature.

\subsection{Influence of $L / D$ ratios and heat treatment temperatures on bulge height of tube}

Figure 7 illustrates the effect of heat treatment temperatures on bulge height for various aspect ratios. From the Fig. 7, it is observed that the bulge height decreased with increase in aspect ratios for all the heat treatment temperatures. Tube material has a capability to bulge up to certain limit without fracture and these limit increase further due to the feeding of the material by axial punches. Higher bulge width will have lesser feeding of the material to compensate the necking at the bulged portion. So, the bulging of the tube specimens decreased with increase in bulge widths in the present study. Bulged tubes of various L/D ratios are illustrated in Fig. 8 . Stress and strain distribution over the bulged tube is shown in Fig. 9. Moreover, the bulge height of the deformed tube is increased with increase in heat treatment temperature up to a temperature of $150^{\circ} \mathrm{C}$ and for $200^{\circ} \mathrm{C}$ and $250^{\circ} \mathrm{C}$ heat treatment temperatures, a slight decrease in bulge height is observed. An increase in bulge height of $4.2 \%, 2.8 \%$ and 


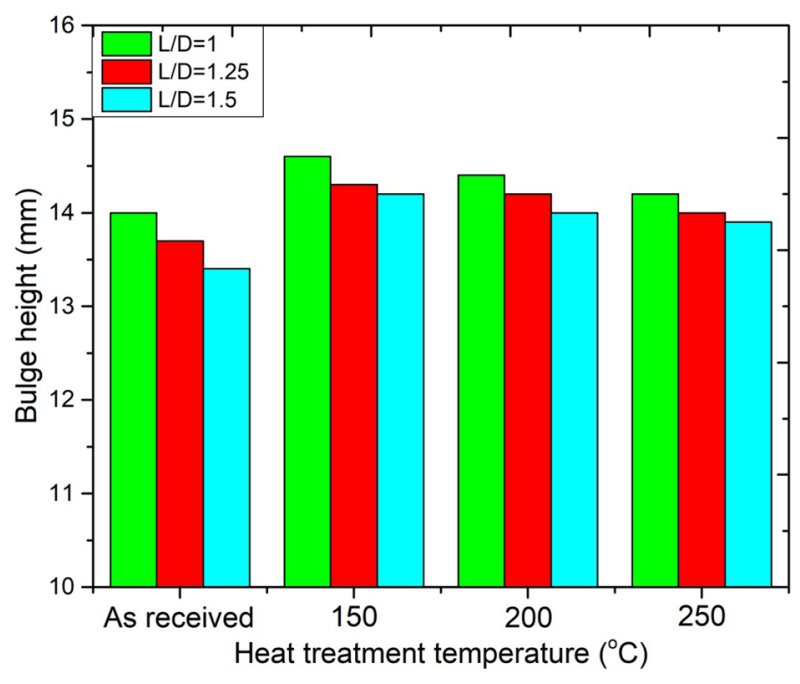

Fig. 7 Effect of heat treatment temperatures on bulge height for various aspect ratios

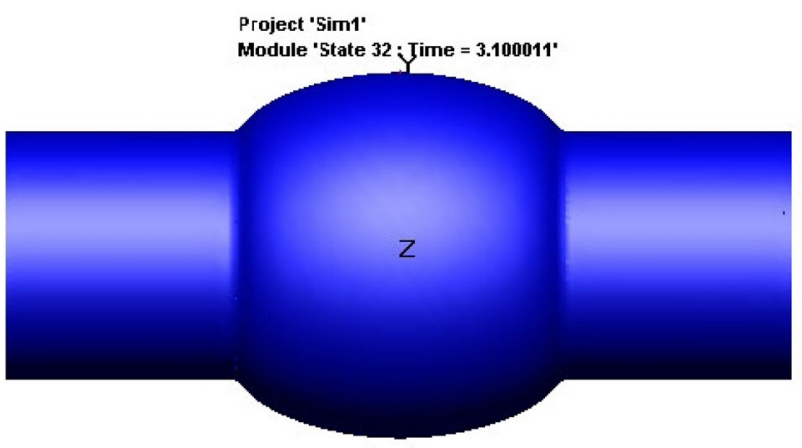

$\mathbf{a}$

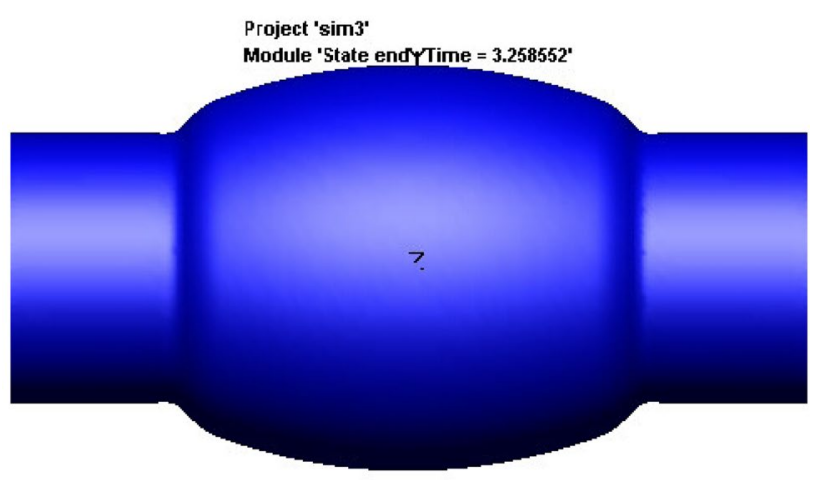

b

Fig. 8 Bulged tubes of various aspect ratios $\mathbf{a} 1 \mathrm{~mm}$ and $\mathbf{b} 1.5 \mathrm{~mm}$

$1.4 \%$ for $150{ }^{\circ} \mathrm{C}, 200^{\circ} \mathrm{C}$ and $250^{\circ} \mathrm{C}$ for L/D ratio of 1 has been observed. The reason for increase in bulge height for $150^{\circ} \mathrm{C}$ is due to the decrease in strength coefficient and strain hardening index as is observed from Table 2 and also increase in elongation \% as observed from Fig. 3.
Literature also revealed that the increase in heat treatment temperature improves the formability of the sheet metal components [46].

\subsection{FLC of various strain paths with heat treatment temperatures effect}

The FLD which are characterized with different limit strains are known as FLC and are divided into two sides' left hand side (LHS) and right hand side (RHS). The limit strain state in the LHS is tension-compression whereas in RHS, it is tension-tension strain state. Strain paths have a capability to change the limit strains. For the establishment of FLD for tube hydroforming process, three different set of simulations as explained in Sect. 3.3 were carried out to attain the limit strains. Constrained bulging leads to an axial shrinkage, whereas in free end bulging, free shrinkage of material in the bulged portion takes place. Tube bulging with axial feeding leads to the plane strain state. The detailed discussion of the simulations conditions were explained clearly in the literature [40]. The longitudinal strain in the free end bulging attains compressive strain whereas the circumferential strain attains tension strain, which matches the LHS of FLD. The fixed end bulging is vice versa for free end bulging and matches the RHS of the FLD. Unusual strain paths be able to obtain with different bulge widths. In this study three unusual bulge widths ( $L / D=1,1.25$ and 1.5 ) were considered.

Variations in loading paths were also alters the strain paths during the tube hydroforming process. In the present study, only one loading condition was considered as shown in Fig. 4. The current work investigated on the heat treatment temperatures effect on the strain paths. The major and minor strains before fracture of the bulged tube were taken based on the TGNC as explained in Sect. 2.4. Figure 10 demonstrates the critical thickness zone (ash colored) based on TGNC of the hydrobulged tube during the THF process. Figure 11 illustrates the consequence of heat treatment temperatures on FLD during the tube hydroforming process. From the Fig. 11, it is clearly understood that the heat treatment temperatures affected the strain paths during the tube hydroforming process. The FLD curve of $200^{\circ} \mathrm{C}$ heat treatment temperature attained higher plain strain state when compared to as received condition. An increase in 19\% is observed for $200{ }^{\circ} \mathrm{C}$ heat treatment temperature when compared to as received condition. Similar results like change in strain paths takes place with change in strain hardening index and yield strength were also observed in the literature as well [47-49].

The FLDs for both the simple and complex strain paths were established for tube hydroforming process. FLDs obtained during the numerical simulations were 
Major stress - Membrane

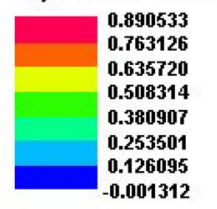

Min $=-\mathbf{0 . 0 0 1 3 1 2}$

$\operatorname{Max}=0.890533$

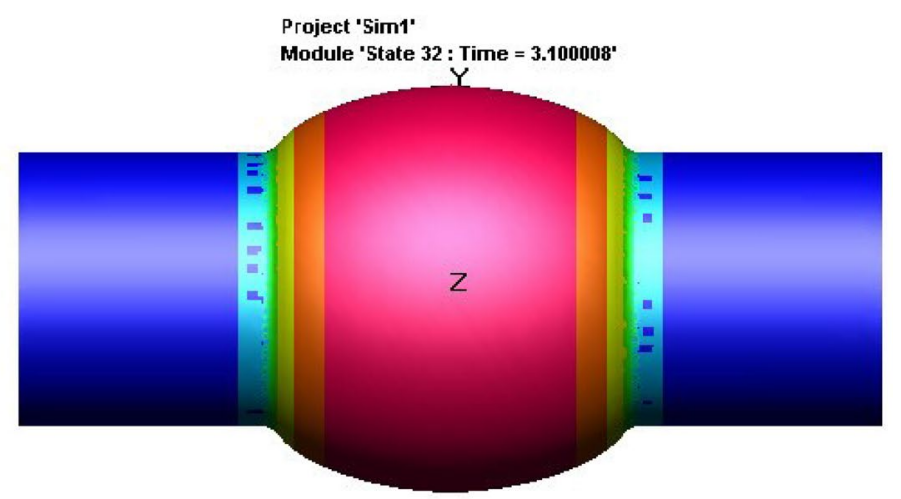

$\mathbf{a}$

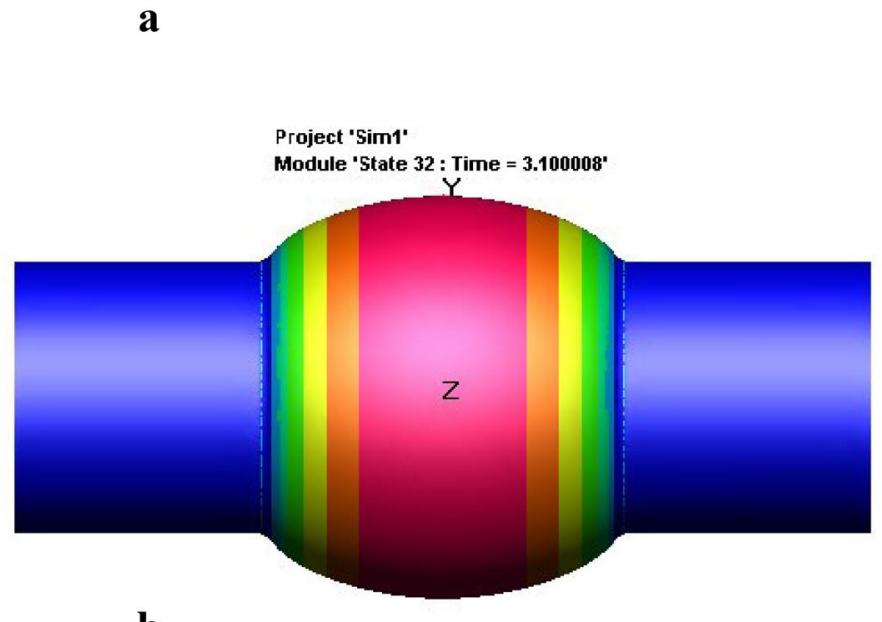

b

hydroforming process before fracture
Major strain - Membrane (true value)

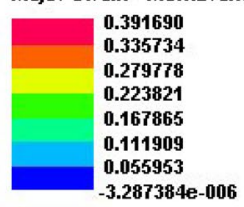

Min $=-3.287384 \mathrm{e}-006$

$\operatorname{Max}=0.391690$

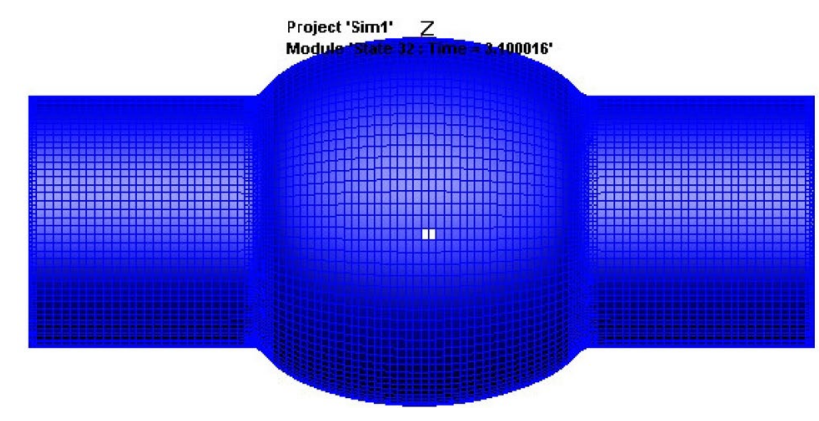

Fig. 10 Critical thickness based on TGNC of the bulged tube

compared with the NADDRG and Sing-Rao models. Figure 12 represents the comparison of both models with the numerically predicted FLD curves for various heat treatment temperatures. From Fig. 12, it is clearly observed that Sing-Rao model correlated well with the numerical predicted FLD when compared to NADDRG model. Similar results like prediction of Sing-Rao model is well suited rather than NADDRG model for the prediction of FLD during sheet metal forming process was observed in the

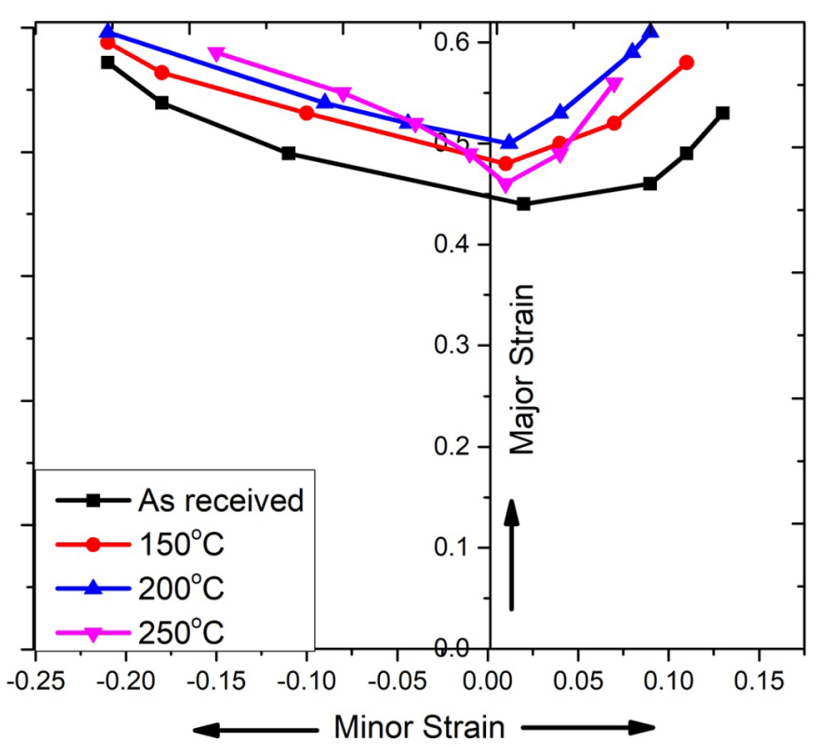

Fig. 11 Effect of heat treatment temperatures on FLD 


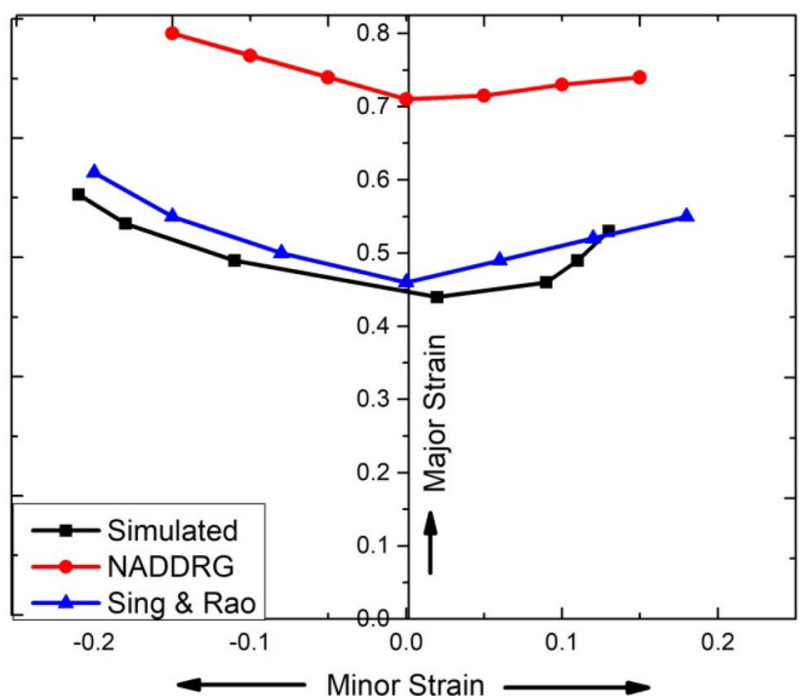

$\mathbf{a}$

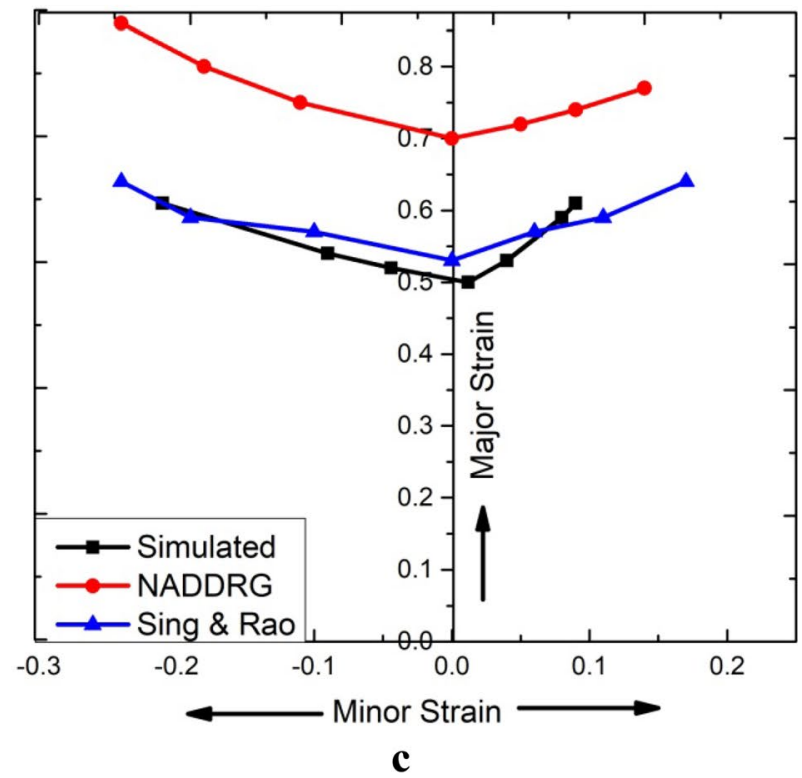

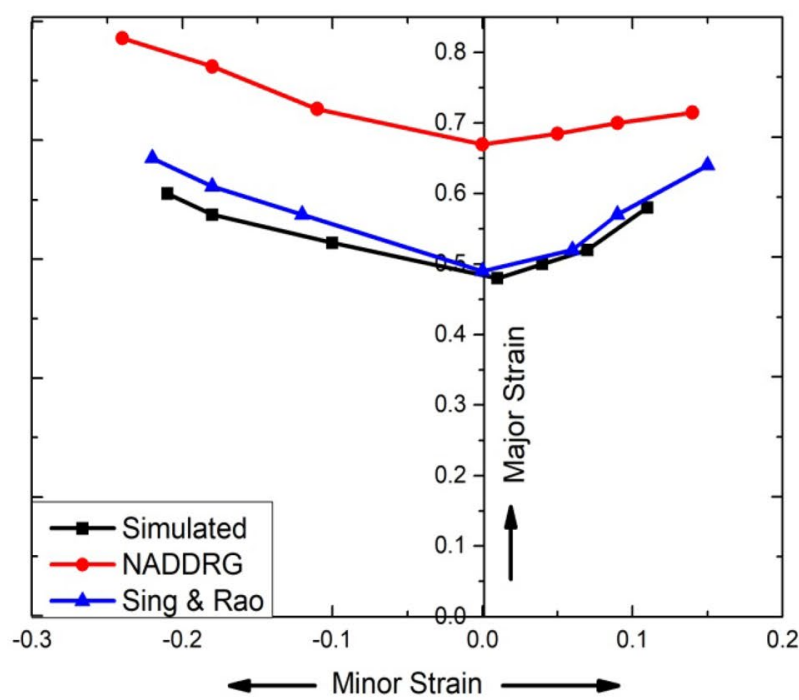

b

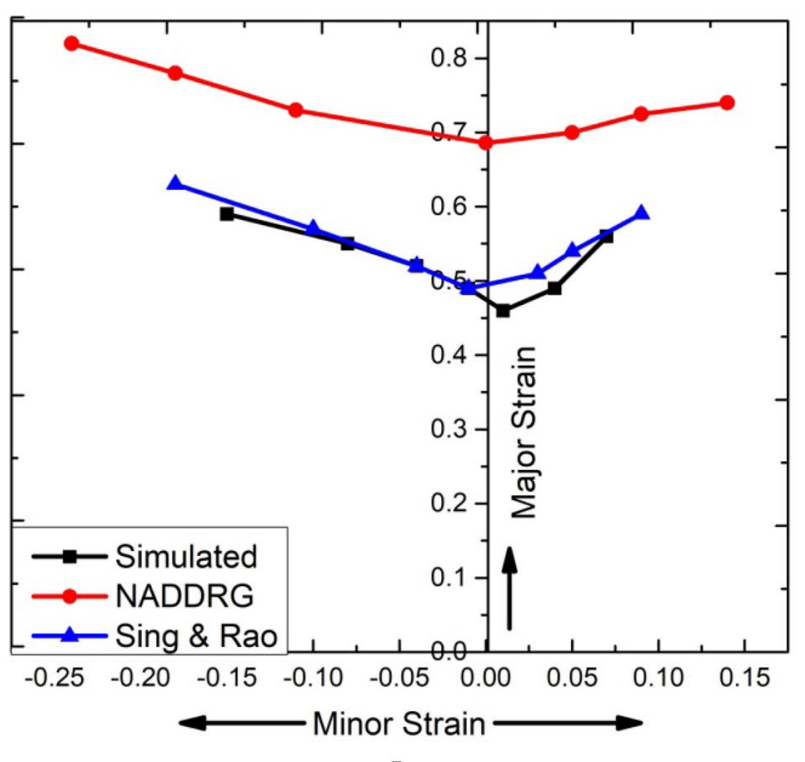

d

Fig. 12 Effect of heat treatment temperatures on FLD for various models a As received, $\mathbf{b} 150^{\circ} \mathrm{C}, \mathbf{c} 200^{\circ} \mathrm{C}$ and $\mathbf{d} 250^{\circ} \mathrm{C}$

literature [50]. All the NADDRG models are over predicted the FLD when compared to the numerical predicted FLD.

\section{Conclusions}

In the present work, numerical simulations were performed on open bulge tube hydroforming. Simulations were carried out by considering the uni-axial tensile test data on various heat treatment temperatures. Heat treatment temperatures effect on formability of SS 304 during tube hydroforming process was considered. The following conclusions were drawn from the current work and are as follows:

1. Heat treatment temperatures affected the formability of the SS 304 tubes during the tube hydroforming process in terms of bulge height and FLD.

2. Heat treatment temperatures and loading conditions along with the aspect ratios effected the strain paths during the process.

3. Internal pressure required for tube bulging decreased with heat treatment temperature up to $150^{\circ} \mathrm{C}$ and further increase in heat treatment temperature increased the internal pressure slightly. 
4. The decrease in internal pressure with heat treatment temperature of $150{ }^{\circ} \mathrm{C}, 200^{\circ} \mathrm{C}$ and $250{ }^{\circ} \mathrm{C}$ are $35.6 \%, 30.6 \%, 27 \%$ respectively when compared to as received condition.

5. An increase in bulge height of $4.2 \%, 2.8 \%$ and $1.4 \%$ for $150^{\circ} \mathrm{C}, 200^{\circ} \mathrm{C}$ and $250^{\circ} \mathrm{C}$ respectively for L/D ratio of 1 has been observed.

6. FLCs improved by heat treatment in comparison with as received tubes.

7. Prediction of Sing-Rao model fitted well with the numerical predicted FLC when compared to NADDRG model.

Acknowledgements The authors would sincerely like to thank the department of metallurgical engineering and material science at IIT Bombay for providing research facilities and also the management of G Pulla Reddy Engineering College (Autonomous), Kurnool for providing the testing facilities and their constant support.

\section{Compliance with ethical standards}

Conflict of interest The authors declare that there is no conflict of interest regarding the publication of this paper.

\section{References}

1. Luo L, Jiang Z, Wei D, Wang X, Zhou C, Huang Q (2018) Microhydromechanical deep drawing of metal cups with hydraulic pressure effects. Front Mech Eng 13(1):66-73

2. Ahmetoglu M, Altan T (2000) Tube hydroforming: state-of-theart and future trends. J Mater Process Technol 98(1):25-33

3. Alaswad A, Benyounis KY, Olabi AG (2012) Tube hydroforming process: a reference guide. Mater Des 33:328-339

4. Omar A, Tewari A, Narasimhan K (2015) Formability and microstructure evolution during hydroforming of drawing quality welded steel tube. J Strain Anal Eng Des 50(7):542-556

5. Chen W, Yang J, Wu X, Lu D, Guo W (2007) Finite element simulations of sheet metal forming under complex strain paths. Front Mech Eng 2(4):399

6. Yuenyong J, Suthon M, Kingklang S, Thanakijkasem P, Mahabunphachai S, Uthaisangsuk V (2018) Formability prediction for tube hydroforming of stainless steel 304 using damage mechanics model. J Manuf Sci E 140(1):011006

7. Hashemi R, Ghazanfari A, Abrinia K, Assempour A (2013) The effect of the imposed boundary rate on the formability of strain rate sensitive sheets using the $\mathrm{M}-\mathrm{K}$ method. J Mater Eng Perform 22(9):2522-2527

8. Zhang R, Lang L, Zafar R (2015) FEM-based strain analysis study for multilayer sheet forming process. Front Mech Eng 10(4):373-379

9. Assempour A, Hashemi R, Abrinia K, Ganjiani M, Masoumi E (2009) A methodology for prediction of forming limit stress diagrams considering the strain path effect. Comput Mater Sci 45(2):195-204

10. He J, Xia ZC, Zhu X, Zeng D, Li S (2013) Sheet metal forming limits under stretch-bending with anisotropic hardening. Int J Mech Sci 75:244-256
11. Aghchai AJ, Shakeri M, Dariani BM (2013) Influences of material properties of components on formability of two-layer metallic sheets. Int J Adv Manuf Technol 66(5-8):809-823

12. Shao Z, Bai Q, Li N, Lin J, Shi Z, Stanton M, Dean T (2018) Experimental investigation of forming limit curves and deformation features in warm forming of an aluminium alloy. Proc Inst Mech Eng Part B J Eng Manuf 232(3):465-474

13. Saxena KK, Drotleff K, Mukhopadhyay J (2016) Elevated temperature forming limit strain diagrams of automotive alloys Al6014-T4 and DP600: a case study. J Strain Anal Eng Des 51(6):459-470

14. Uppaluri R, Reddy NV, Dixit PM (2011) An analytical approach for the prediction of forming limit curves subjected to combined strain paths. Int J Mech Sci 53(5):365-373

15. Reddy PV, Reddy BV, Ramulu PJ (2019) An investigation on tube hydroforming process considering the effect of frictional coefficient and corner radius. Adv Mater Process Technol. https://doi. org/10.1080/2374068X.2019.1707437

16. Li H, Li G, Gao G, Zhang W, Wu X (2018) A formability evaluation method for sheet metal forming with non-linear strain path change. Int J Mater Form 11(2):199-211

17. Raja Satish D, Ravi Kumar D (2019) Formability of AA6061 alloy sheets in warm forming temperature range. Proc Inst Mech Eng Part L J Mater Des Appl 233(3):413-425

18. Dilmec M, Halkaci HS, Ozturk F, Livatyali H, Yigit O (2013) Effects of sheet thickness and anisotropy on forming limit curves of AA2024-T4. Int J Adv Manuf Technol 67(9-12):2689-2700

19. Keeler SP (1961) Plastic instability and fracture in sheets stretched over rigid punches. Doctoral dissertation, Massachusetts Institute of Technology

20. Hashemi R, Mamusi $H$, Masoumi A (2014) A simulation-based approach to the determination of forming limit diagrams. Proc Inst Mech Eng Part B J Eng Manuf 228(12):1582-1591

21. Safikhani AR, Hashemi R, Assempour A (2009) Some numerical aspects of necking solution in prediction of sheet metal forming limits by strain gradient plasticity. Mater Des 30(3):727-740

22. Zhang R, Shao Z, Lin J (2018) A review on modelling techniques for formability prediction of sheet metal forming. Int J Lightweight Mater Manuf 1(3):115-125

23. Asnafi N, Skogsgårdh A (2000) Theoretical and experimental analysis of stroke-controlled tube hydroforming. Mater Sci Eng A 279(1-2):95-110

24. Aue-U-Lan Y, Ngaile G, Altan T (2004) Optimizing tube hydroforming using process simulation and experimental verification. J Mater Process Technol 146(1):137-143

25. Jin K, Guo Q, Tao J, Guo XZ (2017) A modified isotropic-kinematic hardening model to predict the defects in tube hydroforming process. J Mater Eng Perform 26(11):5188-5196

26. Zhang C, Leotoing L, Zhao G, Guines D, Ragneau E (2011) A comparative study of different necking criteria for numerical and experimental prediction of FLCs. J Mater Eng Perform 20(6):1036-1042

27. Hashemi R, Faraji G, Abrinia K, Dizaji AF (2010) Application of the hydroforming strain-and stress-limit diagrams to predict necking in metal bellows forming process. Int J Adv Manuf Technol 46(5-8):551-561

28. Gang LIU, Zhang WD, He ZB, Yuan SJ, Zhe LIN (2012) Warm hydroforming of magnesium alloy tube with large expansion ratio within non-uniform temperature field. Trans Nonferrous Metals Soc China 22:S408-S415

29. Thanakijkasem P, Uthaisangsuk V, Pattarangkun A, Mahabunphachai S (2014) Effect of bright annealing on stainless steel 304 formability in tube hydroforming. Int J Adv Manuf Technol 73(9-12):1341-1349

30. Thanakijkasem P, Pattarangkun A, Mahabunphachai S, Uthaisangsuk V, Chutima S (2015) Comparative study of finite 
element analysis in tube hydroforming of stainless steel 304. Int J Automot Technol 16(4):611-617

31. Naghibi MF, Gerdooei M, Jooybari MB (2016) Experimental and numerical study on forming limit diagrams of 304 stainless steel tubes in the hydroforming process. J Mater Eng Perform 25(12):5460-5467

32. Koc M, Altan T (2002) Prediction of forming limits and parameters in the tube hydroforming process. Int J Mach Tools Manuf 42(1):123-138

33. Keeler SP, Brazier WG (1977) Relationship between laboratory material characterization and press-shop formability. Proc Conf Microalloying 75(1977):517-528

34. Sing WM, Rao KP (1997) Role of strain-hardening laws in the prediction of forming limit curves. J Mater Process Technol 63(1-3):105-110

35. Fracz W, Stachowicz F (2012) Determination of the forming limit diagram of zinc electro-galvanized steel sheets. MetalurgijaZagreb 51(2):161

36. Kumar S, Date PP, Narasimhan K (1994) A new criterion to predict necking failure under biaxial stretching. J Mater Process Technol 45(1-4):583-588

37. Nandedkar VM (2000) Formability studies on a deep drawing quality steel. Doctoral dissertation, Ph. D. thesis, IIT Bombay, Mumbai, India

38. Kalpakjian S, Rajagopal S (1982) Spinning of tubes: a review. J Appl Metalwork 2(3):211-223

39. Suresh K, Regalla SP (2014) Effect of mesh parameters in finite element simulation of single point incremental sheet forming process. Procedia Mater Sci 6:376-382

40. Nikhare C, Narasimhan K (2008) Limit strains comparison during tube and sheet hydroforming and sheet stamping processes by numerical simulation. CMC Tech Sci Press 7(1):1

41. Reddy PV, Reddy BV, Rao PS (2018) A numerical study on tube hydroforming process to optimize the process parameters by Taguchi method. Mater Today Proc 5(11):25376-25381

42. Reddy PV, Ramulu PJ, Madhuri GS, Govardhan D, Prasad PR (2016) Design and analysis of deep drawing process on angular deep drawing dies for different anisotropic materials. In: IOP Conference Series Materials Science and Engineering, vol 149, No. 1, p. 012142. IOP Publishing

43. Kim J, Song WJ, Kang BS (2009) Probabilistic modeling of stressbased FLD in tube hydroforming process. J Mech Sci Technol 23(11):2891-2902

44. Pambhar A, Narasimhan K (2013) Prediction of stress and strain based forming limit diagram during tube hydroforming process. Trans Indian Inst Metals 66(5-6):665-669

45. He Z, Lin Y, Wu J, Yuan S (2011) Study on the formability and deformation behavior of AZ31B tube at elevated temperature by tube bulging test. J Mater Eng Perform 20(7):1278-1284

46. Reddy MV, Reddy PV, Ramanjaneyulu R (2019) Effect of heat treatment and sheet thickness on deep drawing formability: a comparative study. Int J Appl Eng Res 14(3):802-805

47. Chen X, Yu Z, Hou B, Li S, Lin Z (2011) A theoretical and experimental study on forming limit diagram for a seamed tube hydroforming. J Mater Process Technol 211(12):2012-2021

48. Manikandan G, Verma RK, Biswas P (2015) Effect of friction in stretch forming and its influence on the forming limit curve. Proce Inst Mech Eng Part B J Eng Manuf 229(6):973-981

49. Panich $S$, Barlat $F$, Uthaisangsuk $V$, Suranuntchai $S$, Jirathearanat S (2013) Experimental and theoretical formability analysis using strain and stress based forming limit diagram for advanced high strength steels. Mater Des 51:756-766

50. Slota J, Spisak E (2011) Determination of forming limit diagrams considering various models for steel sheets. Acta Mech Slov 15:56

Publisher's Note Springer Nature remains neutral with regard to jurisdictional claims in published maps and institutional affiliations. 